\title{
Reduction of intraspecific aggression in adult rats by neonatal treatment with a selective serotonin reuptake inhibitor
}

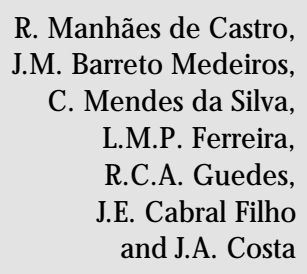

R. M anhães de Castro, J.M. Barreto M edeiros,

C. Mendes da Silva,

L.M.P. Ferreira,

R.C.A. Guedes,

J.E. Cabral Filho and J.A. Costa

Departamento de Nutrição, Centro de Ciências da Saúde, Universidade Federal de Pernambuco, Recife, PE, Brasil

\section{Correspondence \\ R. M anhães de Castro \\ Departamento de Nutrição, CCS \\ UFPE, Cidade Universitária \\ 50670-901 Recife, PE \\ Brasil \\ Fax: +55-81-271-8473 \\ E-mail: rcastro@ nutricao.ufpe.br}

Research supported by CNPq and PROIN/CAPES.

Received December 28, 1999 Accepted November 8, 2000

\section{Abstract}

Most studies suggest that serotonin exerts an inhibitory control on the aggression process. According to experimental evidence, this amine also influences growth and development of the nervous tissue including serotoninergic neurons. Thus, the possibility exists that increased serotonin availability in young animals facilitates a long-lasting effect on aggressive responses. The present study aimed to investigate the aggressive behavior of adult rats (90-120 days) treated from the 1st to the 19th postnatal day with citalopram (CIT), a selective serotonin reuptake inhibitor (20 mg/kg, $s c$, every 3 days). Aggressive behavior was induced by placing a pair of rats (matched by weight) in a box ( 20 x $20 \times 20 \mathrm{~cm}$ ), and submitting them to a 20-min session of electric footshocks (five 1.6-mA - 2-s current pulses, separated by a 4-min intershock interval). When compared to the control group (rats treated for the same period with equivalent volumes of saline solution), the CIT group presented a $41.4 \%$ reduction in the duration of aggressive response. The results indicate that the repeated administration of CIT early in life reduces the aggressive behavior in adulthood and suggest that the increased brain serotoninergic activity could play a role in this effect.

Serotonin has been shown to have multiple functions as a neurotransmitter by exerting modulatory effects on neural excitability (1). There is mounting evidence of its participation in pain sensitivity, body thermoregulation, sleep, feeding behavior and mood (2). Brain areas known to be involved in emotional processes, such as hippocampus, hypothalamus, amygdala and cerebral cortex, are innervated by serotoninergic pathways ascending from mesencephalic nuclei $(3,4)$. Studies on animals and humans have pointed out that the serotoninergic system may play a role in several aggressive behaviors $(4,5)$. An inverse relationship seems to exist between central serotoninergic function and aggressiveness since reducing central serotonin levels facilitates aggression and this increased aggression is impaired by elevation of serotonin beyond normal levels $(2,5)$. Also, the use of animal models of aggressiveness suggests that serotonin receptors are implicated in aggressive responses $(4,6)$. 
Furthermore, experimental evidence indicates that serotonin can influence embryogenesis and growth $(7,8)$ presumably by acting as a developmental signal (9) or a neurotrophic factor (10). A role of serotonin in regulating the development of serotonin neurons themselves has also been demonstrated (7). Moreover, it is well known that very fast growth and development of the nervous system occurs during pregnancy and suckling and pharmacological or nutritional manipulations can induce drastic morphological and functional changes in this process. These changes can become irreversible depending on previous treatment and/or environmental factors $(11,12)$. Thus, it is likely that the neural modifications induced by early serotonin treatment persist until adult life. As a consequence, the possibility exists that the use of serotonin agonists in the initial phase of life could have long-lasting effects on behaviors related to serotoninergic function. Since, to our knowledge, there are no data concerning this point, the investigation of the possible long-term effects of early manipulation of the serotoninergic system is highly desirable. The objective of the present study was to test the hypothesis that the administration of a selective serotonin reuptake inhibitor - citalopram (CIT) - to suckling rats induces changes in aggressiveness during adulthood.

Newborn male Wistar rats from the colony of the Department of Nutrition, Federal University of Pernambuco (Brazil), were assigned randomly to two groups (6 pups per litter) $24 \mathrm{~h}$ after birth. One group (CIT group, 16 rats) received citalopram $(20 \mathrm{mg} / \mathrm{kg}, s c$, dissolved in saline, $1 \mathrm{ml} / \mathrm{kg}$; Lundbeck, Copenhagen, Denmark), and the other (control group, 24 rats) received an equivalent volume of saline $(0.9 \% \mathrm{NaCl})$. The treatments were applied every 3 days from the 1 st to the 19th postnatal day (suckling period). Body weights were determined on the $1 \mathrm{st}, 21 \mathrm{st}$ (weaning) and 90th-120th day. The animals were maintained at a room temperature of 23 $\pm 1^{\circ} \mathrm{C}$, on a light-dark cycle of $12 / 12 \mathrm{~h}$ (lights on at 7:00 a.m.), with free access to water and food. When they reached 90-120 days of age they were submitted to aggressiveness tests. The tests were performed in an acoustically isolated room using a box $(20 \times 20 \times$ $20 \mathrm{~cm}$ ) with the floor consisting of parallel metal bars (interbar distance: $1.3 \mathrm{~cm}$ ) connected to a scrambled electric current source. The test consisted of placing a pair of rats from the same group (matched by weight) in the box, where they received a session of stimuli to induce aggressive responses.

Each stimulus (an electric footshock) consisted of a 1.6-mA - 2-s current pulse. Each session lasted $20 \mathrm{~min}$ and included 5 stimuli separated by a 4-min interval. During the first 3 min of this interval, the duration of the aggressive response was measured with a digital chronometer. The total time of aggressive behavior observation was $900 \mathrm{~s}$. In the last minute of each interval, the data were recorded and the equipment was checked. The aggressive response was defined as the presentation of at least one of the two following behaviors: a) the animals stood up on the hind paws facing each other in a threatening attitude but without direct contact, or b) they maintained evident physical contact (scratching, tooth baring and emission of characteristic vocalization). Data were compared by the two-tailed Student $t$-test (body weight) or by the Mann-Whitney U-test (aggressiveness) with the level of significance set at $\mathrm{P} \leq 0.05$.

Compared to the controls (Table 1), CIT rats showed a reduction in body weight both on the $21 \mathrm{st}(46.8 \%, \mathrm{P}<0.01)$ and 90 th- 120 th day (14.5\%, $\mathrm{P}<0.01)$. A significant difference in aggressive response was also observed (Table 2), with CIT rats presenting a reduced duration of aggressiveness (41.4\% lower than control, $\mathrm{P}<0.02$ ).

The present study showed that chronic administration of CIT during the critical period of brain development impaired the weight evolution and reduced the aggres- 
siveness of the rats. These effects may be related to an alteration of the serotoninergic system occurring during development, as suggested by Palén et al. (8). In a study on chicken embryos, these authors observed that drugs acting on serotonin synthesis and release, or on the activation of serotoninergic receptors may cause disturbances of growth and development in several tissues, including the nervous system, during embryogenesis. Some findings suggest improved neuronal development of serotoninergic neurons of embryogenic nervous tissue treated with serotonin (7). Cultured serotonin neurons of embryogenic rat mesencephalon show an increased density and survival of serotoninergic neurons (9). Although it is unknown whether this higher density of serotonin neurons persists until adult life, our data agree with this possibility. In fact the weight reduction found in the CIT group could be associated with the role of serotonin in feeding control by inhibiting food intake (13).

The reduced aggression duration during adulthood may be also related to the pharmacological manipulation of the serotoninergic system during development, since a close relationship seems to exist between aggressiveness and the function of this neurotransmitter system $(2,4)$. In this context, it is noteworthy that changes in emotional behavior have been already shown in both young and adult rats previously submitted to chronic nutritional injury (14), a condition which is known to alter brain serotonin concentration (15).

The reduction of aggressiveness presented by the CIT group could be related to the serotoninergic action both at pre- and postsynaptic sites. Several studies have indicated such inhibitory role through the activation of serotoninergic receptors (4).

In rats, the elevation of serotonin and 5hydroxyindoleacetic acid levels in the amygdala, diencephalon and brain stem produced a reduction in the latency to muricidal behavior (16).
In the present study a nonspecific effect mediated by serotonin (such as the antinociceptive one) cannot be ruled out because of the high CIT dose used. However, the data support those obtained by others (17), who found a reduction of aggressive behavior in psychotic and borderline human patients treated with CIT. This anti-aggressiveness effect of CIT may be also related to its action on the serotoninergic system. Increased serotonin concentration in the frontal cortex of adult rats has been observed after chronic treatment with high doses of CIT, the same as used here $\left(20 \mathrm{mg} \mathrm{kg}^{-1} \mathrm{day}^{-1}\right.$, ip, for 14 days) (18). This point deserves attention since

Table 1 - Body weight of rats treated with citalopram or saline during suckling.

Rats received citalopram ( $20 \mathrm{mg} / \mathrm{kg}, \mathrm{sc}$; CIT group) or saline $(0.9 \%$ $\mathrm{NaCl}, 1 \mathrm{ml} / \mathrm{kg}$, sc; control group) every 3 days from the 1st to the 19 th day of age. The animals were weighed on the 1st, 21st and 90th-120th day of age. The data are reported as mean \pm SD. $* P<0.01$ compared to the control group at the same age (two-tailed Student t-test).

\begin{tabular}{llll}
\hline \multirow{2}{*}{ Experimental groups } & \multicolumn{3}{c}{ Weight $(\mathrm{g})$} \\
\cline { 2 - 4 } & 1st day & 21st day & 90th-120th day \\
\hline Control group $(\mathrm{N}=24)$ & $7.2 \pm 1.0$ & $48.1 \pm 7.3$ & $334.1 \pm 42.4$ \\
CIT group $(\mathrm{N}=16)$ & $7.0 \pm 0.9$ & $25.6 \pm 5.2^{*}$ & $285.6 \pm 31.0^{*}$
\end{tabular}

Table 2 - Aggressiveness of adult rats treated with citalopram or saline during suckling.

Rats received citalopram ( $20 \mathrm{mg} / \mathrm{kg}, \mathrm{sc}$; CIT group) or saline $(0.9 \%$ $\mathrm{NaCl}, 1 \mathrm{ml} / \mathrm{kg}$, sc; control group) every 3 days from the $1 \mathrm{st}$ to the 19th day of life. Later on, at 90-120 days of age, pairs of animals from the same group were submitted to a footshock session to elicit an aggressive response. The aggressive response was evaluated on the basis of time of aggression (900-s observation). Results are reported as median $(\mathrm{Md})$ and 25 and 75 percentiles $\left(\mathrm{PE}_{25}\right.$ 75). $* P<0.02$ compared to the control group (two-tailed MannWhitney U-test).

\begin{tabular}{llr}
\hline Experimental groups & \multicolumn{2}{l}{ Duration of aggressiveness (s) } \\
\cline { 2 - 3 } & Md & $\mathrm{PE}_{25-75}$ \\
\hline Control group $(\mathrm{N}=24)$ & 679.5 & $51.1-82.9$ \\
CIT group $(\mathrm{N}=16)$ & $398.0^{*}$ & $6.9-72.8$
\end{tabular}


CIT inhibits the reuptake of serotonin, consequently increasing its synaptic availability and enhancing its inhibitory effect on aggressive behavior. On the other hand, the repeated administration of selective serotonin reuptake inhibitors can produce downregulation both of the post- and presynaptic $5-\mathrm{HT}_{1 \mathrm{~B}}$ receptors, in this case improving the serotonin release (19). According to Saudou et al. (20), the 5- $\mathrm{HT}_{1 \mathrm{~B}}$ receptors seem to be very important in the control of aggressive behavior, since mutant mice lacking these receptors presented exacerbated aggressiveness. The fact that CIT administrated during suckling affected aggressive behavior much later in life suggests that 1) permanent mor- phological and/or functional alterations were produced during the period of fast brain development, and 2) these alterations interfere with the behavioral responses of adult rats mediated by the serotoninergic system.

Thus, the reduction of aggressiveness observed in the present study could be associated with neuroadaptive mechanisms developed during the neonatal period which last into adult life.

Further investigations demonstrating possible alterations of the serotoninergic system as a consequence of pharmacological manipulation early in life are necessary to elucidate the mechanisms responsible for the behavioral changes observed in this study.

\section{References}

1. Aghajanian GK \& Marek GJ (1997). Serotonin induces excitatory postsynaptic potentials in apical dendrites of neocortical pyramidal cells. Neuropharmacology, 36 : 589-599.

2. Chopin P, Moret C \& Briley M (1994). Neuropharmacology of 5-hydroxytryptamine $_{1 \mathrm{~B} / 1 \mathrm{D}}$ receptor ligands. Pharmacology and Therapeutics, 62: 385-405.

3. Takeuchi Y (1988). Distribution of serotonin neurons in the mammalian brain. In: Osborne NN \& Hamon M (Editors), Neuronal Serotonin. J ohn Wiley \& Sons, Ltd., New York, 25-56.

4. Olivier B, Mos J , Van Oorschot R \& Hen R (1995). Serotonin receptors and animal models of aggressive behavior. Pharmacopsychiatry, 28 (Suppl): 89-90.

5. Kyes RC, Botchin MB, Kaplan J R, Manuck SB \& Mann JJ (1995). Aggression and brain serotoninergic responsiveness: response to slides in male macaques. Physiology and Behavior, 2: 205-208.

6. Sánchez C \& Hyttel J (1994). Isolationinduced aggression in mice: effects of 5hydroxytryptamine uptake inhibitors and involvement of postsynaptic $5-\mathrm{HT}_{1 \mathrm{~A}}$ receptors. European J ournal of Pharmacology, 264: 241-247.

7. Whitaker-Azmitia PM (1991). Role of serotonin and other neurotransmitter receptors in brain development: basis for developmental pharmacology. Pharmacological Reviews, 43: 553-561.

8. Palén $K$, Thörneby $L \&$ Emanuelsson $H$
(1979). Effects of serotonin antagonists on chick embryogenesis. Wilhelm Roux's Archives of Developmental Biology, 187: 89-103.

9. Liu J \& Lauder J M (1992). Serotonin promotes region-specific glial influences on cultured serotonin and dopamine neurons. Glia, 5: 306-317.

10. Yan W, Wilson CC \& Haring J H (1997). 5$\mathrm{HTl}$ a receptors mediate the neurotrophic effect of serotonin on developing dentate gramile cells. Developmental Brain Research, 98: 185-190.

11. de-Castro RM, Cabral-Filho J E, Costa J A, Costa FBR, Gallindo MAC \& Hecksher CA (1993). Neonatal treatment with naloxone causes permanent hyperalgesia in rats. Brazilian J ournal of Medical and Biological Research, 26: 747-751.

12. Noback CR \& Eisenman LM (1981). Some effects of protein-calorie undernutrition on the developing central nervous system of the rat. Anatomical Record, 201: 67-73.

13. Simansky KJ (1996). Serotonergic control of the organization of feeding and satiety. Behavioural Brain Research, 73: 37-42.

14. Teodósio MR, Cabral Filho JE, Guedes RCA, Costa J A, Costa FRB \& Silva AT (1979). Learned and emotional behavior in chronically malnourished rats. Acta Physiologica Latinoamericana, 29: 255262.

15. Stern WC, Miller M, Forbes WB, Morgane PJ \& Resnick O (1975). Ontogeny of the levels of biogenic amines in various parts of the brain and in peripheral tissue in normal and protein malnourished rats. Experimental Neurology, 49: 314-326.

16. Sakata T, Fuchimoto $H$, Kodama J \& Fukushima M (1975). Changes of brain serotonin and muricide behavior following chronic administration of theophylline in rats. Physiology and Behavior, 15: 449453.

17. Syvälahti EKG, Kallioniemi $H$ \& Lehto $H$ (1994). Citalopram in patients with unsatisfactory response to neuroleptics: an open follow-up study. Methods and Findings in Experimental and Clinical Pharmacology, 16: 49-55.

18. Arborelius L, Nomikos GG, Hertel P, Salmi $P$, Grillner $P$, Höök BB, Hacksell $U \&$ Svensson TH (1996). The 5-HT1A receptor antagonist (S)-UH-301 augments the increase in extracellular concentrations of 5-HT in the frontal cortex produced by both acute and chronic treatment with citalopram. Naunyn-Schmiedeberg's Archives of Pharmacology, 353: 630-640.

19. Briley M \& Moret C (1993). Neurobiological mechanisms involved in antidepressant therapies. Clinical Neuropharmacology, 16: 387-400.

20. Saudou F, Amara DA, Dierich A, LeMeur $M$, Ramboz S, Segu L, Buhot MC \& Hen R (1994). Enhanced aggressive behavior in mice lacking $5-\mathrm{HT}_{1 \mathrm{~B}}$ receptor. Science, 265: 1875-1878. 